is not even mentioned. His treatment of fractures differs somewhat from that which is generally adopted; he dots not apply splints till the eighth or tenth day (considering it unnecessary to keep the ends of the bone in contact, before ossific matter begins to be deposited), the limb, till then, being merely surrounded with a bandage, and a folded sheet kept wet with cold water, to subdue or prevent inflammation. In fractures of the lower extremity (except that of the patella), he has always kept the knee first bent at a right angle and afterwards perfectly straight. It might be argued in opposition to this practice, that iıjury must be produced and the cure retarded, by moving the fractured ends in order to reduce them at so late a period; but facts are better than theory, and the successful event of many hundred cases without a single failure, shows that the practice is at least attended with neither danger nor inconvenience, while, on the other hand, it cannot be denied that many a limb has been lost or endangered by tightly inclosing it in splints, immedialely after the accident. In compound fractures of the lower extremity, the author recommends that the bones should be reduced and the limb kept straight from the first, as all motion here must necessarily be injurious. In his treatment of stricture he has used the armed or caustic bougie very extensively, and prefers it to all other methods, where the common bougie is not sufficient, and where the stricture is neither of great length nor of cartilaginous structure. His own words are, "I have no hesitation in saying, that where I cannot get rid of the stricture by the wax bougie, I prefer them to all other means that $I$ have ever employed ; and I am disposed to believe that it is owing to their abuse, and not their fair use, that the practice has been brought so very much in to discredit." "The plan of treatment that 1 almost invariably adopt with a patient under stricture is, in the first place, to altempt its removal by dilatation with the common was bougie; that mode failing, to try with the same kind of bougie to break down the ob. struction, if it can be done with very gentle means; and suppusing that we are toiled in both these ways, then to apply the bougie armed wilh the linar caustic."-pp. 253, 234.

The only thing with which we have to find fault in the work is the style, which is confused and exceedingly inelegant: how. ever, we must be content with the useful and valuable information which it contains, and not expect " the pen of a ready. writer" from a man who has been all his life most actively, and almost incessantly, employed in the practical duties of his pro. fession, and who has performed no less thao 270 amputations.

$-$

CASE OF

ANEURISM OF THE INNOMINATA, SUCCESSFULLY TREATED BY TYING THE CAROTID ARTERY.

By Dr. Motт, Professor of Surgèry, at New York.

(Communicated in a letter to Mr. WA RnRap, Surgeon to the King.)

New York, February 15, 1830. $S_{I R},-W i t h$ much pleasure 1 send you the accompanying case of aneurism of the innominata, treated by tying the carotid artery. It is the first of the kind which has been performed in this country, and I am persuaded that its success will be interesting to you as additionally confirmatory of the great principle so ably, and so fully, established by yourself, which improvement must be numbered with the greatest in moderu surgery; conferring upon the talent, genius, and acquirements of its advocate the highest honour and the most lasting fame.

As applied to aneurismal tumours, hitherto deciding the fate of the patient, and pronouncing lim the certain victim of incurable disease, it must receive the approbation of the profession and the gratitude of the philanthropist. For the particulars of the case I take the liberty of referring you to the accompanying paper, and $I$ an happy to present this account of the first operation performed in America for the cure of aneurism of the innominata, to the discoverer and first successful performer of it in Europe.

With sentiments of respect, I zemain, Sir,

Your obedient servant, VALENTINe Motr, M.D.,

To James Wardrop, Esq. Professor of Surgery.

Case.-Moses IR. Gardner, retatis 51 , a farmer, of sound constitution and good habits of life, applied to me sometime in March for advice. He gave the following relation of bis case :-About three years 
ago, while occupied in removing. a building, $\mid$ be felt; at the wrist no pulse could be and so compelled to lift heavy weights, he found; the pulsations of the arteries of the was attacked with pain in the upper and back left side were also natural; - his general part of the neck; this lasted until the month of January, when it extended to the right shoulder and arm, and continued to the fol-lowing May; it then partially subsided, and he observed his voice was becoming hoarse, which he attributed to exposure, and consequent cold. About eighteen months since, while shaving, he discovered a small swelling at the upper part of the breast-bone, but did not remark any throbbing in it until sometime afterwards. He had consulted a surgeon, but had received no positive opinion on the case. Upon examination I found, above the sternum, a pulsating tumour, about the size of a pigeon's egrg, spreading some distance under the clavicular and sternal portions of the right sterno-mastoideus muscle, in the course of the subclavian artery, and extending as low down as the second rib, compressing more or less the bronchial tubes, and producing, on the least coughing or exercise, a wheezing, not unlike that of astlima. He shrunk from the least pressure upon it, complaining of impeded respiration, followed by pain; its pulsations were synchronous with those of the heart, and decidedly aneurismal.

After fully explaining to him the nature of his disease, and its probable fatal termi. nation should it increase and be left to itself, $\mathrm{J}$ advised bim to return to his home, to avoid all exertion, to be occasionally bled, and confine himself principally to a vegeta. ble diet; but, should he observe the least increase, either in the tumour or any of his symptoms, to come again to me, and I would then decide on the propriety of an operation. I have since occasionally seen him; lie seemed to understand his case fully, and was very desirous to take the chance of the operation; but as I could not observe any material change in the disease, I recommended him to pursue the same directions, and wait patiently until some alteration should occur.

Sept. 12th, he again came to the city. I found that the tumour above the sternum lad much increased, and, upon a careful application of the stethoscope, that it had evidently encroached more upon the chest. The "bruit de soufflet" could be heard; the thoracic viscera were sound, and the respiratory murmur distinct throughout. In either speaking, walking, or coughing, his respiration was very much impeded, and almost entirely suspended by the least pressure upon the tumour. The action of the right carotid was much more feeble than that of the left, and no pulsation conld be felt in its branches; the xight subclavian, external to the scaleni muscles, was natural, while the axillary and brachial arteries could hardly health was good.

In reflecting on this case, and compar. ing the relative situation of the parts, I was persuaded the aneurism was of the arteria innominata, involving the subclavian and the root of the carotid. With this conclusion, I considered it a proper case for the operation proposed and successfully performed by Mr. Wardrop, whose scientific researches and masterly views of the sub. ject, have heen so fully confirmed by himself and others. I now thought delay unnecessary, and the patient being willing to abide by my judgment, after having stated to him the chances of the operation, I resolved on its performance. From the evident interruption of the circnlation in the right arm, and the apparent efforts of $\mathrm{Na}$ ture to effect a spontaneous cure, I determined upon tying the carotid first, to observe the result, and afterwards to secure the subclavian should it be required.

On the 20th September, I operated ; the artery was taken up in the usual manner, and no material change was observed.

27 th, 9 А.м: Slept well, and feels refreshed; thinks there is more room, as he expresses it, in breathing; complains of a little soreness of the tonsils in swallowing; pulse 58, regular, and tranquil; the skin natural; pulsation and size of the tu. mour evidently diminished.

9 р.M. Much more restless from mental alarm; pulse 68 , and tense; in other respects the same as in the morning; being habituated to laudanum, was permitted to take a teaspoonful.

28 th, 9 A.m. Slept well; breathes easily, and says he takes a more satisfactory breath than he did before the operation; feels much less of the pulsation in the tumour; pulse 63 , and not so tense; skin natural, and cough much less. Ordered a dose of col. magnesia and Epsom salts.

9 р.м. Has passed a comfortable day. His wife, who arrived from the country since the morning, expressed her surprise at the improvement in his voice and breathing, as well as at the difference in the beating. Pulse of the right radial artery very dis. tinct, but intermitting from ten to fifteen beats; in the left arm 80 , and stronger; cougls frequently, and expectorates freely; skin natural; tongue a little white; salts have not operated. Ordered the dose to be repented, and if restless after its operation, to take his usual anodyne.

29 th. Saluted me this morning upon entering his room, with a full and fine voice, and said he was well enough to call on me. His cough and expectoration much less. I found him lying down, and breath- 
ing quietly; pulse 71 , and regular. The radial artery of the right arm beating as last evening, with fewer intermissions, but of longer continuance; skin over the tumour more wrinkled; pulsation less and weaker.

8 P.M. As well as in the morning; takes a full breath, without the least wheezing ; pulsation in the right wrist very distinct and regular; in the left, 26 in the minute.

30 th. Found him lying more recumbent than at any former period; pulse 70 , and regular; right radial artery does not beat quite so firmly as yesterday; wound dis. charging a little; was dressed.

Oct. 2d. Says he now feels as if he would get well; cough rather more troublesome; pulse 75 ; pulsation of the right radial artery the same.

3rd. Cough and bronchial effusion very much diminished by the operation of a cathartic; pulse 68 .

4th. Feels very well; passed a good night; all his symptoms improved; pulse $7+$; can bear any degree of pressure upon the tumour without the least pain or dif. ficulty of breathing.

$10 \mathrm{th}$. Continues to mend, and is sanguine as to his recovery ; tumour very much diminished in size, and pulsation hardly perceptible ; cough less troublesome; left pulse 66 , right very feeble.

16th. Ligature came away last night ; the tumour above the sternum, and pulsation, entirely disappeared; cough and breathing better; voice nearly natural ; pulse 66 , only now and then a very faint pulsation of the right radial artery; right hand a little swelled, and feels numbed; complains of the want of power to close it.

22nd. Wound just healed; weakness of the arm very considerable; fingers very thick and clumsy; whole arm swelled, and pits upon pressure; no pulse in the right radial artery; breathing easy; cough and expectoration much less; can sleep easy in any position, which he has not been able to do for many months.

26th. Left town this morning for his residence in New Jersey.

(Signed) Valentine Motr, M.D. Prof. of Surg.

\section{ON THE VENOMOUS SERPENTS OF} SOUTH AMERICA.

THE numerous contradictions in which the effect and treatment of the bites of venomous serpents is involved, induced Dr. Renzger, a German physician, to bestow particular attention upon this subject, during a six years' residence in Paraguay; the re* sult of his observations, extracted from Meckel's Archives, will, we trust, be read with interest, as it may serve to throw light upon some points regarding this interesting subject.

Paraguay possesses a great quantity of poisonous serpents, of the genera crotalus, lachesis, cophias, elaps, \&c.; the bite of all of which is attended with the symptoms of poisonous wounds terminating, in most cases, in death; on the whole, there is no difference in the symptoms, whether the bite be produced by the one or the other kind of serpent, except in the intensity, which, however, very often varies in the bite from the same species, and even the same individual. The bite of large and old serpents is -more dangerous than that of small and young ones; this does not, how. ever, depend on the intensity of the poison, but on the quantity in which it is secreted. Dr. Renzger made six rattlesnakes, of three days old, bite a young rat, which died within a few hours; two other rats, bitten by one of them, exhibited scarcely any symptom. The dangerous effect also depends on the state of excitement of the animal ; it is irritated, the bite hardly ever fails of being fatal. Dr. Renzger, however, justly observes, that this might as well depend on the bite being inflicted more deeply under these curcumstances. He also confirms the fact of the poisonous effect gradually lessening when the animal has been exhausted by repeated bites. It isi known, that serpents generally fall in to a sort of torpidity during the winter; this holds good also of the serpents in Paraguag, though in a somewhat less degree than in those of northern climates; and it is stated by Dr. Renzger, that the first bite, after awaking from this torpid state, is generally peculiarly dangerous : and he observed the same thing after the casting of the skin, during the period of which they are blind, and consequently keep quiet and immovable. The danger also varies according to the situation of the bite; the wounds of vascular parts, and particularly of large blood-vessels, are generally followed by speedy death; the effect is much slower when the poison is applied to denuded tendons, or even nerves; and in parts which possess no vessels at all, as in the callous cuticle of the soles, no morbid effect at all is observed; after violent exertion, and during increased circulation of the blood, the poison is also asserted to act far more rapidly, contrary to the common belief. The operation of the poison is precisely the same on natives and Europe: ans, as Dr. R. had many opportunities of observing.

If the wound be inflicted under the most 